\title{
Dieulafoy lezyonu tanılı hastalarda endoskopik tedavi başarısı ve takip sonuçları
}

\author{
Success of endoscopic treatment in patients with dieulafoy lesion and follow-up results
}

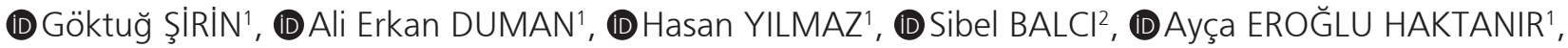

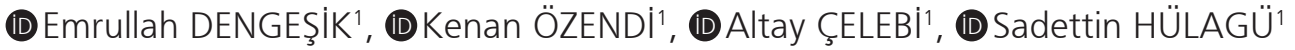

Kocaeli Üniversitesi Tıp Fakültesi ${ }^{1}$ Iç Hastalıkları Anabilim Dalı Gastroenteroloji Bilim Dalı, ${ }^{2}$ Biyoistatistik ve Tıp Bilişimi Anabilim Dalı, Kocaeli

\begin{abstract}
Giriş ve Amaç: Kliniğimizde Dieulafoy lezyonu tanısı konulan hastalar için yapılan endoskopik tedavileri, bu endoskopik tedavilerin başarı ve komplikasyon oranlarını ve işlem sonrası takip döneminde gelişen yeniden kanama ve hastaneye yatış oranlarını tespit etmeyi amaçladık. Gereç ve Yöntem: Haziran 2015 - Haziran 2020 tarihleri arasında, Kliniğimiz Endoskopi Ünitesi'nde, gastrointestinal sistem kanaması nedeniyle, endoskopik inceleme yapılmış hastaların dosyaları ve endoskopi raporları geriye dönük olarak değerlendirildi. Dieulafoy lezyonu tanısı doğrulanmış hastaların demografik özellikleri, başvuru öncesi şikayetleri, yapılmış tetkik ve endoskopik işlemlerin sonuçları, endoskopik müdahalenin içeriği ve işlem başarısı, işlem sonrası erken veya geç komplikasyon ya da yeniden kanama olup olmadığı analiz edildi. Bulgular: Toplam 48 hasta çalışmaya alındı. Hastaların 16'sında lezyonun jejenumda bulunduğu görüldü (\%33.3). Mortalite hastaların ikisinde (\%4.2) gerçekleşti. En sık kullanılan endoskopik tedavi yöntemi kombine teknik olup ( $n=30), 29$ hastada hemoklips tek başına veya kombinasyon tedavisi olarak uygulanmıştı. On hastada, endoskopik müdahale sonrası erken $(n=6)$ veya geç $(n=4)$ dönemde yeniden kanama gelişti. Kombine teknik uygulanan hastalarda, tek bir teknik uygulanan hastalara göre yeniden kanama oranının daha düşük olduğu görüldü ( $p=0.027)$. Hemoklips içeren kombine tedaviler sadece hemoklips uygulamasıyla ya da argon plazma koagülasyon içeren kombine tedaviler sadece argon plazma koagülasyon uygulamasıyla karşılaştırıldığında ise anlamlı farklılık görülmedi (sırasıyla, $p=0.300$ ve $p=0.550$ ). Sonuç: Dieulafoy lezyonları, standart endoskopik yöntemler kullanılarak kanama odağı tespit edilemeyen tüm hastalarda, ayırıcı tanı seçenekleri arasında bulunmalı ve ince bağırsaklar, mutlaka olası tutulum açııından endoskopik olarak incelenmelidir. Mekanik ve termal yöntemleri içeren kombine uygulamaların kullanılması yeniden kanama oranlarını azaltabilir.
\end{abstract}

Anahtar kelimeler: Dieulafoy lezyonu, endoskopik tedavi, yeniden kanama, gastrointestinal sistem kanaması

\section{GíRiş}

Gastroenteroloji bölümüne acil koşullarda yapılan müracaatların en sık görülen sebeplerinden biri gastrointestinal sistem (GIS) kanamalarıdır. GiS kanamalarının en sık nedeni ise peptik ülser ve gastrointestinal sistemde yerleşmiş erozyonlardır (1).

\footnotetext{
Iletişim: Göktuğ şíîn

Kocaeli Üniversitesi Tıp Fakültesi, ľç Hastalıkları Anabilim Dalı,

Gastroenteroloji Bilim Dalı 41380, Kocaeli, Türkiye

Tel: +90 2623037575 • Faks: +90 2623037003 • E-mail: gsirin@live.com
}

Background and Aims: The goal of this study was to determine the endoscopic treatments performed in patients diagnosed with Dieulafoy lesion in our clinic, the effectiveness and complication rates of these endoscopic treatments, and the rates of re-bleeding and hospitalization during the post-procedure follow-up period. Material and Methods: Files and endoscopy records of patients who underwent endoscopy at our clinic's endoscopy unit due to gastrointestinal system bleeding were evaluated retrospectively between June 2015 and June 2020. Furthermore, demographic characteristics, complaints or examinations conducted for bleeding prior to application, and content and success of the endoscopic procedures, whether there are early or late complications or re-bleeding, were also analyzed in patients with established diagnoses of Dieulafoy lesion. Results: A total of 48 patients were included in the study. The lesion was observed in the jejunum of 16 patients (33.3\%). Further, mortality occurred in two (4.2\%) patients. The most widely used endoscopic treatment method was the combined technique $(n=30)$, and hemoclips were administered alone or as a combination therapy in 29 patients. In ten patients, re-bleeding occurred early $(n=6)$ or late $(n=4)$ period after endoscopic intervention. The rate of re-bleeding was found to be lower in patients who underwent the combined technique compared to patients who underwent a single technique $(p=0.027)$. There was no substantial difference $(p=0.300$ and $p$ $=0.550$, respectively) when combined therapies containing hemoclips were compared either with hemoclip application or combined treatments containing argon plasma coagulation with only argon plasma coagulation application. Conclusion: Dieulafoy lesions should be among the differential diagnostic options for all patients whose bleeding focus cannot be identified using standard endoscopic methods, and the small intestines should be endoscopically examined for possible involvement. Moreover, the use of combined applications involving mechanical and thermal methods may reduce the rate of re-bleeding.

Key words: Dieulafoy lesion, endoscopic treatment, re-bleeding, gastrointestinal system bleeding

Gastrointestinal sistem kanaması ile sağlık kuruluşuna başvuru yapan hastalarda, görece nadir görülen ve çoğu kez kanamaya neden oluncaya kadar belirgin şikayet yaratmayan Dieulafoy lezyonuna (DEL) rastlanma sıklığı \%1$2^{\prime} \operatorname{dir}(2)$.

Şirin G, Duman AE, Yllmaz H, et al. Success of endoscopic treatment in patients with dieulafoy lesion and follow-up results. The Turkish Journal of Academic Gastroenterology 2020;19:136-142. DOI: 10.17941/agd.836616

Geliş Tarihi: 13.09.2020 • Kabul Tarihi: 13.11.2020 
Mukozaya ulaştığında kalibrasyonu azalmayan, geniş submukozal arterioler yapılardan oluşan bu lezyonlar, sıklıkla masif kanamaya neden olurlar (3). Kanamadıkları dönemde ve ilk endoskopik incelemede ise görülemeyebilirler. Nadir görülmeleri ve kanama şekillerinin mevcut farklılığı, bu lezyonların tanısının konulmasını ve tedavisinin yapılmasını zorlaştırmaktadır $(3,4)$.

Biz bu çalışmamızda kliniğimizde DEL tanısı konulan hastalar için yapılan endoskopik tedavileri, bu endoskopik tedavilerin başarı ve komplikasyon oranlarını ve işlem sonrası takip döneminde gelişen komplikasyon, yeniden kanama ve hastaneye yatış oranlarını tespit etmeyi amaçladık.

\section{GEREÇ ve YÖNTEM}

Haziran 2015-Haziran 2020 tarihleri arasında, Hastanemiz Gastroenteroloji Kliniği Endoskopi Ünitesi'nde, gastrointestinal sistem kanaması nedeniyle, endoskopik inceleme [gastroskopi, kolonoskopi, push enteroskopi (PE) veya çift balonlu enteroskopi (ÇBE)] yapılmış hastaların dosyaları ve endoskopi raporları geriye dönük olarak tarandı. Hasta bilgilerine, Gastroenteroloji Polikliniği hasta dosyaları, Hastane Bilgi Sistemi ve Endoskopi Kayıt ve Raporlama Programı üzerinden erişildi. Bu incelemelerin ardından DEL tanısı almış olan hastalar, çalışmaya dahil edilme açısından değerlendirildi. Tanı almış hastaların endoskopi raporları incelendiğinde, tarif edilen lezyon karakteristikleri ve endoskopik görüntüleri tanı ile uyumlu olmayan hastalar çalışma dışı bırakıldı. Tanımlama için Dy ve arkadaşları tarafından tanımlanmış endoskopi kriterleri kullanıldı (5).

Hastaların demografik özellikleri, varsa komorbiditeleri, başvuru ve işlem öncesi şikayetleri, kanamaya yönelik olarak yapılmış tetkikleri, daha önce almış oldukları tedaviler ve sağlık öz geçmişleri kayıt edildi. Lezyonların yerleşim yeri, bu lezyonlar için endoskopik müdahale yapılıp yapımadığı, yapılmış olan endoskopik müdahalenin içeriği ve işlem başarısı, işlem sonrası erken (işlem esnasında) veya geç (işlem sonrası dönemde) komplikasyon olup olmadığı, erken dönemde (0-28 gün) ve geç dönemde (29-365 gün) yeniden kanama olup olmadığı ve yeniden endoskopik müdahale gerekip gerekmediği değerlendirildi. Hastanede yatış süresi, verilen tedaviler, kan trasfüzyon ihtiyacı not alındı ve hasta takip notları incelendi.

İşlem başarısı, endoskopik inceleme esnasında kanama odağının tespit edilmesi ve aktif kanamanın endoskopik müdahale ardından durduğunun görülmesi olarak tanımlandı. Yeniden kanama ise endoskopik veya cerrahi olarak durdurulmuş kanamanın yeniden başlaması ve bu- nun endoskopik olarak teyit edilmesi olarak kabul edildi. İşlem başarısı veya yeniden kanama üzerinde uygulanan endoskopik tekniğin etkisinin olup olmadığı araştırıldı. 2020/254 proje numaralı çalışmanın yapılması için gerekli etik kurul onayı Üniversitemiz Lokal Etik Kurulundan alındı (GOKAEK-2020/14.16; tarih 28.8.2020).

\section{İstatistiksel Analiz}

İstatistiksel değerlendirme, IBM SPSS 20.0 (IBM Corp., Armonk, NY, USA) paket programı kullanılarak yapıldı. Normal dağılıma uygunluk Shapiro-Wilk testi ile değerlendirildi. Normal dağılım gösteren nümerik değişkenler ortalama \pm standart sapma ve aralık, normal dağılım göstermeyen nümerik değişkenler ortanca (aralık) olarak ifade edildi. Kategorik değişkenler ise frekans (yüzde) olarak verildi.

Gruplar arasındaki farklılık, normal dağılıma sahip olan nümerik değişkenler için bağımsız örneklem t testi ile, normal dağılıma sahip olmayan nümerik değişkenler için Mann-Whitney U testi ile belirlendi. Kategorik değişkenler arasındaki ilişkiler Ki-kare analizi ile değerlendirildi. İki yönlü hipotezlerin testinde $p<0.05$ istatistiksel önemlilik için yeterli kabul edildi.

\section{BULGULAR}

Çalışmanın yapıldığı tarih aralığında 62 hastaya Dieulafoy lezyonu (DEL) tanısı konulduğu görüldü. On dört hasta, endoskopik görüntüleri ve/veya rapordaki lezyonun tarifi tanı kriterlerini karşılamadığı için, çalışma dışında bırakıldı. Toplam 48 hasta çalışmaya alındı. Hastaların 36 tanesi erkek (\%75) ve 12 tanesi kadın olup, ortalama yaş $68.9 \pm 12.7$ ve yaş aralığı 24-93 idi. Hastaların çoğunluğunun 60 yaşından büyük olduğu (n=25) (\%52.1) görüldü.

Hastaların 31 tanesi (\%64.6) dış merkezden yönlendirilmişken, 17 tanesi doğrudan hastanemize başvurmuştu. Başvuru anında hemoglobin ( $\mathrm{Hb}$ ) düzeyleri ortalama 7.8 $\pm 3.1 \mathrm{mg} / \mathrm{dL}$ iken (3.8-13.2), uluslararası normalleştirilmiş oran (INR) değerlerinin antikoagülan kullanan hasta grubunda ( $n=10)$ ortalama $7.7 \pm 3.05$ (4-14) ve antikoagülan kullanmayan hasta grubunda $(n=38)$ ise $0.9 \pm 0.17$ (0.5-1.2) olduğu görüldü. Hastaların tümü hospitalize edilerek takip edilmiş ve hepsi parenteral proton pompa inhibitörü (PPi) tedavisi almıştı. Hastalarda başvuru anında en sık tespit edilen, kanamayı düşündüren bulgu melena olup, bunu sırasıyla hematokezya, melenayla birlikte hematemez ve sadece hematemez izlemekteydi (Tablo 1).

Çalışmaya katılan hastalarda komorbidite sıklığının artmış olduğu ve hastaların yarısından fazlasında $(n=27)$ (\%56.25) en az bir kronik hastalık bulunduğu görüldü. 


\section{Tablo 1. Hastaların demografik özellikleri ve ilk başvuru öncesi klinik verileri}

\begin{tabular}{|c|c|}
\hline Özellikler & Değerler \\
\hline Yaş (ortalama \pm SS) & $68.9 \pm 12.7$ \\
\hline \multicolumn{2}{|l|}{ Cinsiyet, (n) (\%) } \\
\hline Erkek & $36(75)$ \\
\hline Kadın & $12(25)$ \\
\hline \multirow[t]{2}{*}{ Dış merkez sevkli hasta, (n)/Doğrudan başvuru, (n) } & $31 / 17$ \\
\hline & Ortanca (aralık) \\
\hline Başvuru öncesi kanama deneyimi, (gün) & $16(3-88)$ \\
\hline Başvuru öncesi endoskopik inceleme sayısı, (n) & $3(1-12)$ \\
\hline Başvuru öncesi endoskopik müdahale sayısı, (n) & $2(1-5)$ \\
\hline \multicolumn{2}{|l|}{ Başvuruda kanamayı düşündüren bulgu, (n) (\%) } \\
\hline Melena & $24(50)$ \\
\hline Hematokezya & $12(50)$ \\
\hline Melena ve hematemez & $6(12.5)$ \\
\hline Hematemez & $6(12.5)$ \\
\hline Başvuru öncesi kan transfüzyon miktarı, (ünite) & $5(2-34)$ \\
\hline Antikoagülan/Antiagregan/NSAil kullanımı, $(n=20)(\% 41.6)(n / n / n)$ & $10 / 16 / 12^{*}$ \\
\hline Komorbiditesi olan hasta sayısı (HT, DM, KAH, KY, KBY, SVH) (n) (\%) & $27(56.25)^{\star \star}$ \\
\hline Geçirilmiş batın cerrahisi/Gis cerrahisi, (n)/(n) & $9 / 4$ \\
\hline
\end{tabular}

*Aynı hastada birden fazla ilaç kullanımı; **Aynı hastada birden fazla hastalık.

Çalışma hastalarının demografik özellikleri ve klinik verileri Tablo 1'de özetlendi.

Yapılan endoskopik işlemlerin ardından, en sık jejenumda olmak üzere (n=16), GiS'in farklı bölümlerinde DEL tespit edildiği görüldü. Jejenumun ardından giderek azalan sıklıkta midede $(n=14)$, duodenum $(n=8)$ ve ileumda $(n=6)$, en az ise kolonda $(n=4)$ bu lezyon ve lezyona bağlı kanama tespit edilmiş idi. Lezyonlar midede daha çok kardiya ve fundusta $(n=10)$, duodenumda daha çok 3. ve 4. kıtada $(n=6)$ ve jejenumda ise daha çok proksimal bölümde $(n=10)$ yerleşmiş̧i.

Kanama odağının, duodenum 3. kıtada yerleşmiş hastaların 2'sinde ağızdan yollanan kolonoskopi cihazı ile 1'inde push enteroskopi cihazı kullanılarak ve 4. kıtada yerleşmiş olan hastaların yine bir tanesinde push enteroskopi cihazı kullanılarak bulunmuş olduğu görüldü. Duodenum 4. kıtadaki lezyonların 2 'sinin ve jejenum $(n=16)$ ile ileumda $(n=6)$ yerleşmiş lezyonların tamamının $(n=24)$ tanısı ise ÇBE seansı esnasında konulmuştu (Tablo 2). Tanının konulması için yapılan endoskopik işlem sayısı ortalama $1.37 \pm 0.84$ (1-5) idi.
Hastaların tümüne endoskopik müdahale yapıldığı ve en sık kullanılan yöntemin, mekanik bir yöntem olan hemoklips (tek veya kombine) ( $n=29)$ (\%60.4) uygulaması olduğu görüldü. Kanamanın kontrol altına alınması için 19 olguda (\%35.4) hemoklips dışı farklı teknikler [argon plazma koagülasyon (APC), adrenalin uygulaması + APC veya adrenalin uygulaması + hemostatik forseps] kullanılmıştı. Hastaların 30 tanesinde (\%62.5) kombine tedavi uygulanmış iken, 18'inde tek bir çeşit endoskopik tekniğin kullanıldığı görüldü. Endoskopik tedavi ile kanama kontrolü 47 hastada sağlanabilmiş (\%97.9); 1 hasta cerrahiye verilmek zorunda kalınmıştı (Tablo 2).

İşleme bağlı komplikasyon 5 hastada (\%10.4) görüldü. Aspirasyon pnömonisi nedeniyle iki hasta yoğun bakım ünitesinde takip ve tedavi edilirken, 1 hasta geç dönemde (8. gün) gelişen perforasyon nedeniyle cerrahiye verildi. 1 hastada işlem sonrası pankreatit ve bir hastada ise akut böbrek yetmezliği gelişti. Bu hastaların tümü, hastanede yapılan takip ve tedavi sürecinin ardından, kalıcı sekel olmaksızın taburcu edilebildi. İşleme bağlı komplikasyon nedeniyle ölüm görülmedi (Tablo 2). 
Tablo 2. Dieulafoy lezyonu tanısı ve endoskopik tedaviye ait özellikler

\begin{tabular}{|c|c|}
\hline Özellikler & Değerler \\
\hline \multicolumn{2}{|l|}{ Tanı konulan endoskopi cihazı, $(n=48)$} \\
\hline Çift balonlu enteroskopi & 24 \\
\hline Gastroskopi/Kolonoskopi & $16 / 6$ \\
\hline Push enteroskopi & 2 \\
\hline \multicolumn{2}{|l|}{ Dieulafoy lezyonu lokalizasyonu, n (\%) } \\
\hline \multicolumn{2}{|l|}{ Mide, $(n=14)(29.2)$} \\
\hline Kardiya & 5 \\
\hline Fundus & 5 \\
\hline Korpus & 3 \\
\hline Antrum & 1 \\
\hline \multicolumn{2}{|l|}{ Duodenum, $(n=8)(16.6)$} \\
\hline Bulbus & 2 \\
\hline 2./3./4. kita & $-/ 3 / 3$ \\
\hline Jejunum, (n=16) (33.3) (Proksimal/Distal) & $(10 / 6)$ \\
\hline \multicolumn{2}{|l|}{ Illeum, $(n=6)(12.5)$} \\
\hline \multicolumn{2}{|l|}{ Kolon, $(n=4)(8.3)$} \\
\hline Çekum ve ileoçekal valvül & 1 \\
\hline Çıkan kolon & 1 \\
\hline Transvers kolon & - \\
\hline İnen kolon & - \\
\hline Sigmoid kolon & 1 \\
\hline Rektum ve rektosigmoid birleşke & 1 \\
\hline Endoskopik tedavi yapılan hasta sayısı, n (\%) & $48(100)$ \\
\hline \multicolumn{2}{|l|}{ Endoskopik tedavi yöntemi, (n) } \\
\hline Adrenalin + Hemoklips & 10 \\
\hline Hemoklips & 8 \\
\hline Adrenalin + Hemoklips + Adrenalin & 3 \\
\hline Adrenalin + APC & 6 \\
\hline Adrenalin + APC + Hemoklips & 4 \\
\hline APC + Hemoklips & 4 \\
\hline APC & 10 \\
\hline Adrenalin + Hemostatik forseps & 3 \\
\hline Endoskopik tedavi başarısı, n (\%) & $47(97.9)$ \\
\hline Kanama kontrolü için cerrahi gereksinimi, n (\%) & $1(2.1)$ \\
\hline Endoskopik işlem komplikasyonu, n (\%) & $5(10.4)$ \\
\hline Perforasyon (işlem esnasında/işlem sonrası) & $-/ 1^{*}$ \\
\hline Aspirasyon pnömonisi & $2 * *$ \\
\hline Cerrahi gereksinimi & $1^{*}$ \\
\hline İşlem sonrası yoğun bakım ünitesi ihtiyacı & $2 * \star$ \\
\hline Mortalite & - \\
\hline Diğer*** & 2 \\
\hline
\end{tabular}

APC: Argon plazma koagülasyon.

*Perforasyon gelişen hasta cerrahiye verildi;

${ }^{* *}$ Aspirasyon pnömonisi gelişen iki hasta yoğun bakım ünitesinde takip ve tedavi edildi;

${ }_{\star \star *} 1$ hastada akut pankreatit ve 1 hastada akut böbrek yetmezliği gelişti.
Endoskopik ( $n=47)$ ve cerrahi $(n=1)$ müdahale ile başarıyla kanama kontrolü sağlanan 48 hastanın, ortalama $36.4 \pm 11.2$ ay süreyle yapılan takibinde; 6 hastada erken dönemde, 4 hastada geç dönemde yeniden kanama oldu. Kanama kontrolü için cerrahi uygulanan tek hastada, erken postoperatuvar dönemde yeniden kanama gelişmiş olduğu görüldü.

Takip döneminde 2 hasta (E/K:1) mortal seyretti (\%4.2). Endoskopik müdahale sonrası erken dönemde yeniden kanama (3. gün) ve eş zamanlı gelişen akut koroner sendrom nedeniyle bir erkek hasta ve kanama kontrolü için uygulanan cerrahi sonrası yeniden oluşan kanaması endoskopik olarak durdurulan, ancak postoperatuvar dönemde multiorgan yetmezliği gelişen bir kadın hasta hayatını kaybetti. Iki hastanın da hem antiagregan hem antikoagülan tedavi almakta olduğu, üçer adet komorbiditesinin bulunduğu, yaşlarının sırasıyla 82 ve 88 olduğu görüldü.

Yeniden kanama oluşan diğer tüm vakalarda $(n=8)$, kanama endoskopik yöntemler kullanılarak başarılı şekilde kontrol altına alındı (\%100) ve hastalar şifa ile taburcu edilebildi. Yeniden kanayan hastalar için yapılan endoskopik müdahaleler, sıklıkla monoterapi şeklinde ve APC uygulanarak yapılmış idi. Bu endoskopik işlemlere bağlı komplikasyon veya ölüm ise görülmedi. Erken ve geç dönemde yeniden kanama oluşan hastalarda, tespit edilen DEL lokalizasyonu ve uygulanan endoskopik müdahaleler Tablo 3'te gösterildi.

Yaş; başvuru anındaki Hb düzeyi, trombosit sayısı, INR veya albümin değeri; hastanede yatış süresi parametrelerinin, işlem başarısı veya yeniden kanama sıklığı üzerinde etkili olmadığı görüldü ( $p>0.05)$.

Uygulanan teknikler arasında karşılaştırma yapıldığında, kombine teknik uygulanan hastalarda, tek bir teknik uygulanan hastalara göre yeniden kanama oranının daha düşük olduğu tespit edildi $(p=0.027)$. Hemoklips içeren kombine tedaviler sadece hemoklips uygulaması ile karşılaştıııldığında ya da APC içeren kombine tedaviler sadece APC uygulaması ile kıyaslandığında ise anlamlı farklılık tespit edilmedi (sırasıyla, $p=0.300$ ve $p=0.550$ ) (Tablo 4).

\section{TARTIŞMA}

Görece seyrek görülen patolojiler olduğu düşünülen Dieulafoy lezyonlarının, günümüzde giderek artan sıklıkta tespit edildiği ve bu nedenle yapılan hastane yatışlarının yükselme gösterdiği bildirilmektedir (6). İnsanların yaşam süresinin uzamasına bağlı yaşlı birey nüfusunun artması, buna bağlı vasküler yatağı etkileyen kronik hastalıkların ve/veya ilaçların kullanım oranının yükselmesi, tanı me- 
todlarının gelişmesi ya da farkındalığın artmış olması bu trendin oluşumunda rol oynuyor olabilir.

Kimi zaman yaşamı tehdit edici ölçüde ciddi gastrointestinal sistem kanamasına yol açabilen değişken kanama paterni ve çok farklı lokalizasyonlarda yerleşebilme yeteneği, tanının konulmasını zorlaştırabilmekte ve standart endoskopik yöntemlerin kullanılması tanı için yetersiz kalabilmektedir. Nitekim tanısı ünitemizde konulan 48 DEL vakasının 31 tanesi, yapılan standart incelemeler ile lezyon tespit edilemediği için tarafımıza yönlendirilen hastalardır. Bu hastaların 24'ünde tanı, çift balonlu enteroskopi kullanımı sayesinde konulabilmiştir.

Çalışma grubumuzdaki hastaların \%75'inin erkek olduğu ve yarısından fazlasının 60 yaşın üzerinde bulundu- ğu görülmüştür. Erkek baskın cinsiyet, yapılmış çoğu DEL çalışmasında belirtilen bir husus olup, kesin sebebi bilinmemektedir (7). Öte yandan yaşı popülasyonda bu lezyonun daha fazla tespit edilmesi, hem daha sık bulunan komorbiditelerin hem de daha çok kullanılan antiagreganların veya nonsteroidal antiinflamatuvar ilaçların (NSAii) zedeleyici etkisinin, bu lezyonların oluşmasını ve daha kolay kanamasını tetiklediği hipoteziyle uyumlu gibi görünmektedir. Gerçekten de hastalarımızın yaklaşık olarak beşte ikisinin bu ilaçları kullandığı ve beşte üçünün ise hipertansiyon (HT), diabetes mellitus (DM), koroner arter hastalığı (KAH), kalp yetmezliği (KY), kronik böbrek yetmezliği (KBY) veya serebrovasküler hastalık (SVH) gibi kronik bir hastalığa sahip olduğu tespit edilmiştir.

\section{Tablo 3. Yeniden kanama gelişen hastaların hastanede yatış süreci ve takip sonuçları}

\section{Özellikler}

Hastanede yatış süresi, (gün)

Hastanede kan transfüzyonu ihtiyacı, (ünite)

Mortalite, $(n)$ ve nedeni

Erken dönemde yeniden kanama (0-28 gün), (n)

Erken dönemde yeniden kanama lokalizasyonu, (n) (M/D/J/I/K)

Erken dönemde yeniden kanama kontrolü için endoskopik/cerrahi girişim, (n)

Erken dönemde yeniden kanama kontrolü için uygulanan endoskopik teknik, (M/D/J) (n)

Geç dönemde yeniden kanama (29-365 gün), (n)

Geç dönemde yeniden kanama lokalizasyonu, (n) (M/D/J/i/K)

Geç dönemde yeniden kanama kontrolü için endoskopik/cerrahi girişim, ( $n$ )

Geç dönemde yeniden kanama kontrolü için uygulanan endoskopik teknik, (M/J/i) (n)

n: Sayl; AKS: Akut koroner sendrom; ÇoY: Çoklu organ yetmezliği; M: Mide; D: Duodenum; J: Jejunum; I: Ileum; K: Kolon; HK: Hemoklips; AD: Adrenalin ile skleroterapi; APC: Argon plazma koagülasyon.

*Bir hasta: Kanama kontrolü için yapılan cerrahi sonrası anastamoz hattında yeniden kanama gelişen hasta.

Tablo 4. Uygulanan endoskopik tekniğin işlem başarısı ve yeniden kanama üzerine etkisi

\begin{tabular}{|c|c|c|c|}
\hline Endoskopik Teknik (n) & Yeniden Kanama (+) & Yeniden Kanama (-) & P Değeri \\
\hline Kombine/Tek, (n/n) & $3 / 7$ & $27 / 11$ & 0.027 \\
\hline \multicolumn{4}{|l|}{ Tek, (n) } \\
\hline Sadece APC & 2 & 8 & 0.584 \\
\hline Sadece HK & 2 & 6 & 0.279 \\
\hline Kombine $(H K+) / H K,(n / n)$ & $2 / 2$ & $19 / 6$ & 0.300 \\
\hline Kombine $(A P C+) / A P C,(n / n)$ & $1 / 2$ & $13 / 8$ & 0.550 \\
\hline
\end{tabular}

n: Sayı; APC: Argon plazma koagülasyon; HK: Hemoklips; HK+: Hemoklipsin bulunduğu kombine teknik; APC+: Argon plazma koagülasyonun bulunduğu kombine teknik. 
Bu lezyonların en sık görüldüğü yerin mide olduğunu bildiren çok sayıda çalışma bulunmaktadır (8). Oysa bizim çalışmamızda, hastaların 14 tanesinde DEL'nun midede yerleşmiş olmasına karşıı 30 hastada lezyonun ince bağırsakta bulunduğu (22 hastada jejunum ve ileumda) görülmüştür. Bunun nedeni, hastalarımızın çoğunun dış merkezden refere edilmiş olmasına bağlı olarak, bu merkezlerde enteroskopik inceleme yapılmadığı veya yapılamadığı için, rutin endoskopik inceleme ile tespit edilemeyecek lokalizasyonlarda yerleşmiş lezyonlara sahip hasta sayımızın görece fazlalığı olabilir. Diğer yandan bu sayının yüksek olması, DEL'nın ince bağırsakta zannedildiğinden daha sık bulunduğuna ve özellikle rutin endoskopik inceleme ile lezyon tespit edilemeyen Gis kanaması durumunda, ince bağırsakların dikkatli bir şekilde incelenmesi gerektiğine de işaret etmektedir. Bu anlamda çalışmamız, Dieulafoy lezyonlarının ince bağırsakta, özellikle jejunumda sıklıkla bulunabildiğine vurgu yapan kimi çalışmalar ile uyumludur (9).

Bu lezyonların tedavisi için uygulanan endoskopik işlemlerin yıllar içinde artan başarısı, bu tedavi modalitesini en popüler seçenek haline getirmiştir (10). Güncel çalışmada da hastaların çok büyük kısmında (\%97.9) lezyonlar tespit edilerek kanama kontrolü sağlanabilmiştir.

Literatürde farklı endoskopik tekniklerin değişen ölçüde etkili olduğunu gösteren çalışmalar bulunmaktadır. Bu çalışmaların bir kısmında mekanik yöntemlerin bir kısmında ise tekli tedavilere kıyasla kombine yöntemlerin etkili olduğuna dikkat çekilmektedir (11-13).

Çalışmamızda ise kanamanın ilk kontrolü açısından, kullanılan teknikler ya da kombinasyonlar arasında aşikar bir fark bulunamamıştır. Ancak yeniden kanama gelişiminin kombine tedavi uygulanan hastalarda, kombine olmayan tedavi yapılan hastalara göre istatistiksel olarak anlamlı ölçüde daha az olduğu görülmüştür ( $p=0.027)$ (12).

Bunun dışında, teknikler kendi arasında kıyaslandığında veya hemoklipsli kombine tedaviler ile tek başına hemoklips uygulaması ya da APC içeren kombine tedaviler ile sadece APC uygulaması karşılaştırıldığında da, yeniden kanama oluşması açısından anlamlı bir fark bulunamamıştır. Anlamlı farkın bulunmamış olması, yeniden kanama gerçekleşen hasta sayısının düşük olmasının (\%20.8) bir sonucu olabilir. Serimizdeki yeniden kanama oranı, literatürdeki kimi veriler ile uyumlu olmasına rağmen, bazı çaIışmalarda elde edilen oranlara göre yüksek bulunmuştur (11). Bu durum, takip süremizin çoğu sadece endoskopik işlem sonrası 30 günlük süreyi dikkate alan çalışmaların aksine çok daha uzun olmasının (36.4 \pm 11.2 ay) sonucu olabileceği gibi, vaka bazında endoskopik tedaviye dirençli olguların çalışmamızda görece fazla sayıda bulunmasına da bağlı olabilir. Nitekim çalışma hastalarının birinde, endoskopik tedaviye dirençli olduğu için cerrahi uygulanmasına rağmen, cerrahi sonrası dönemde endoskopik müdahale gerektirecek şiddette yeniden kanama gelişmiştir.

Endoskopik yöntemlerin gelişmesi ve Dieulafoy lezyonlarının tıbbi yönetimindeki iyileşme, mortalite oranlarının azalmasına yol açmıştır. Eski tarihli çalışmalarda \%80 seviyesinde olan bu oran, günümüzde belki de tedavi için cerrahi yöntemlerin çok daha az kullanılmasının bir sonucu olarak, \%10'ların altına düşmüştür $(10,14)$. Çalışmamızda mortalite oranı \%4.2 ( $n=2)$ olarak gerçekleşmiş olup; ölen hastalardan biri uygulanan cerrahi tedavi sonrası gelişen komplikasyon nedeniyle kaybedilmiştir. Bu sonuç, acil cerrahi tedavilerin yüksek komplikasyon oranları ile seyredebileceğine vurgu yapan literatür bilgisini desteklemektedir. Akpınar ve ark'nın 2016'da yayınladığı çalışmalarında \%38.9 olarak tespit ettikleri ölüm oranı, bizim çalışmamızdaki orandan yüksek olup, bunda hasta popülasyonlarının yaş ortalamasının bizimkinden daha yüksek olmasının ve çalışmamızın aksine, kadın hasta oranının çok daha fazla olmasının etkisi var gibi durmaktadır (15).

Çalışmamızın Dieulafoy lezyonlarının endoskopik yönetimi ve sonuçları hakkında ayrıntılı bilgiler veren, yüksek vaka sayısına ve görece uzun takip süresine sahip önemli bir çalışma olduğunu, ancak bazı kısıtlamalarının bulunduğunu düşünüyoruz. Özellikle retrospektif olarak dizayn edilmesi nedeniyle, araştırılan patoloji görece nadir görüldüğü için, sadece endoskopi raporları değil hasta dosyaları, bilgi kartları ve hastane bilgi sistemi veri girişleri de değerlendirmeye katılmış olmasına rağmen, araştırılan parametreler hakkında bilgi kaybı yaşanmış olabilir. Diğer yandan çalışma tek merkezde yapılmış olduğu ve endoskopik işlemleri yapan endoskopistler deneyim ve kişisel yetenekleri açısından sınıflandırılmadığı için, elde edilen sonuçların genellenmesi konusunda problem yaşanabilir.

Sonuç olarak; Dieulafoy lezyonları, standart endoskopik yöntemler kullanılarak kanama odağı tespit edilemeyen ve Gis kanaması şüphesi bulunan tüm hastalarda, ayırıc tanı seçenekleri arasında bulunmalı ve bu hastalarda ince bağırsaklar, mutlaka olası tutulum açısından endoskopik olarak incelenmelidir. Bu lezyonlara bağlı kanama, endoskopik olarak başarıyla tedavi edilebilmesine ră̆men, yeniden kanama oluşabileceği akılda tutulmalıdır. Eğer imkanlar elveriyorsa, mekanik ve termal yöntemleri içeren kombine uygulamaların kullanılması ve tek başına adrenalinle skleroterapi yapılmasından kaçınılması, yeniden kanama oranlarını azaltabilir. Endoskopik tedavinin başarısız olması durumunda cerrahi tedavi bir seçenek olabilmekle birlikte, komplikasyon oranlarının özellikle yaşlı ve komorbiditesi bulunan bireylerde yüksek olabileceği akılda tutulmalıdır. 


\section{Etik Standartlara Uyum:}

Yazarlar, bu yazının hazırlanması ve yayınlanması aşamasında herhangi bir çıkar çakışması olmadığını beyan ederler. Bu makale için herhangi bir finansal destek alınmamıştır. Insan katılımcıları içeren çalışmalarda gerçekleştirilen tüm prosedürler, kurumsal ve/veya ulusal araştırma komitesinin etik standartlarına ve 1964 Helsinki beyanına ve daha sonraki değişikliklere veya karşılaştırılabilir etik standartlara (GOKAEK-2020/14.16; tarih 28.8.2020) uygun olarak gerçekleştirilmiştir. Çalışmaya dahil edilen tüm katıımcılardan bilgilendirilmiş onam alınmıştır.

\section{KAYNAKLAR}

1. British Society of Gastroenterology Endoscopy Committee. Non-variceal upper gastrointestinal haemorrhage: guidelines. Gut 2002;51(Suppl 4):iv1-6.

2. Marangoni G, Cresswell AB, Faraj W, Shaikh H, Bowles MJ. An uncommon cause of life-threatening gastrointestinal bleeding: 2 synchronous Dieulafoy lesions. J Paediatr Surg 2009;44:441-3.

3. Pessia B, Romano L, Giuliani A, et al. Rare case of upper gastrointestinal bleeding: Dieulafoy's lesion of duodenum. A case report. An Med Surg 2019;45:19-21.

4. Pineda-De Paz MR, Rosario-Morel MM, Lopez-Fuentes JG, Waller-Gonzalez LA, Soto-Solis R. Endoscopic management of massive rectal bleeding from a Dieulafoy's lesion: Case report. World J Gastrointest Endosc 2019;11:438-42.

5. Dy NM, Gostout CJ, Balm RK. Bleeding from the endoscopicallyidentified Dieulafoy lesion of the proximal small intestine and coIon. Am J Gastroenterol 1995;90:108-11.

6. Chakinala RC, Solanki S, Haq KF, et al.Dieulafoy's Lesion: Decade-Long Trends in Hospitalizations, Demographic Disparity, and Outcomes. Cureus 2020;12:e9170.

7. Jamanca-Poma Y, Velasco-Guardado A, Pinero-Perez C, et al. Prognostic factors for recurrence of gastrointestinal bleeding due to Dieulafoy's lesion. World J Gastroenterol 2012;18:5734-8.

8. Scmulewitz N, Baillie J. Dieulafoy lesions; a review of 6 years experience of a tertiary referral centre. Am J Gastrenterol 2001;96:168994
9. Dulic-Lakovic E, Dulic M, Hubner D, et al; Austrian Dieulafoy-bleeding Study Group. Bleeding Dieulafoy lesions of the small bowel: a systematic study on the epidemiology and efficacy of enteroscopic treatment. Gastrointest Endosc 2011;74:573-80

10. Baxter M, Aly EH. Dieulafoy's lesion: current trends in diagnosis and management. Ann R Coll Surg Engl 2010;92:548-54.

11. Alis $\mathrm{H}$, Oner $\mathrm{OZ}$, Kalayci $\mathrm{MU}$, et al. Is endoscopic band ligation superior to injection therapy for Dieulafoy lesion? Surg Endosc 2009;23:1465-9.

12. Chung IK, Kim EJ, Lee MS, et al. Bleeding Dieulafoy's lesions and the choice of endoscopic method: comparing the hemostatic efficacy of mechanical and injection methods. Gastrointest Endosc 2000;52:721-4.

13. Cheng CL, Liu NJ, Lee CS, et al. Endoscopic management of Dieu lafoy lesions in acute nonvariceal upper gastrointestinal bleeding. Dig Dis Sci 2004;49:1139-44.

14. Alshumrani G, Almuaikeel M. Angiographic findings and endovascular embolization in Dieulafoy disease: a case report and literature review. Diagn Intervent Radiol 2006;12:151-4.

15. Akpınar MY, Öztaş E, Aras D, et al. Dieulafoy lezyonunda endoskopik tedavi. Akademik Gastroenteroloji Dergisi 2016;15:102-5. 